Supporting Information

\title{
Restructuring of Porphyrin Networks Driven by Self-Assembled Octanoic Acid Monolayer on $\mathrm{Au}(111)$
}

\author{
Yongman Kim, ${ }^{\dagger, \dagger}$ YoungJae Kim, ${ }^{\dagger, \dagger}$ and Jeong Young Park ${ }^{*, \dagger}$, \\ ${ }^{\dagger}$ Department of chemistry, Korea Advanced Institute of Science and Technology (KAIST), Daejeon \\ 305-701, Republic of Korea \\ tCenter for Nanomaterials and Chemical Reactions, Institute for Basic Science, Daejeon 305-701, \\ Republic of Korea \\ * Corresponding author E-mail: jeongypark@kaist.ac.kr
}



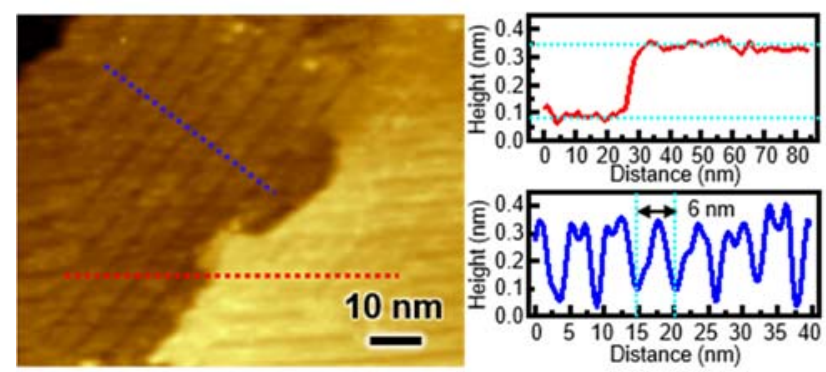

Figure S1. STM features of $\mathrm{Au}(111) /$ mica surface in $\operatorname{air}\left(\mathrm{V}_{\mathrm{s}}=+1.0 \mathrm{~V}, \mathrm{I}_{\mathrm{t}}=400 \mathrm{pA}\right)$. A typical surface structure of $\mathrm{Au}(111)$ is observed with a herringbone reconstruction structure.

(a)

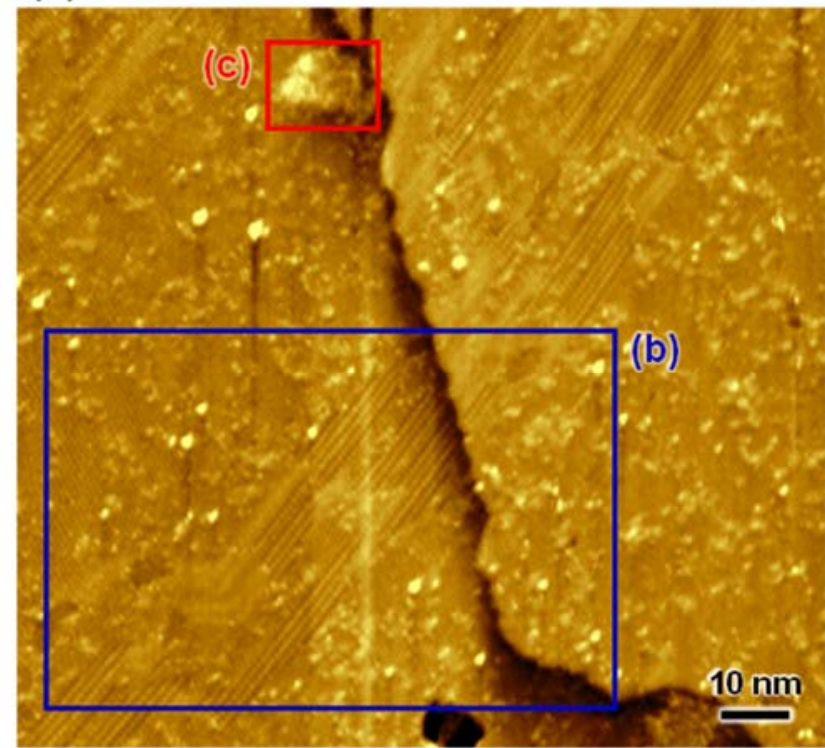

(c)
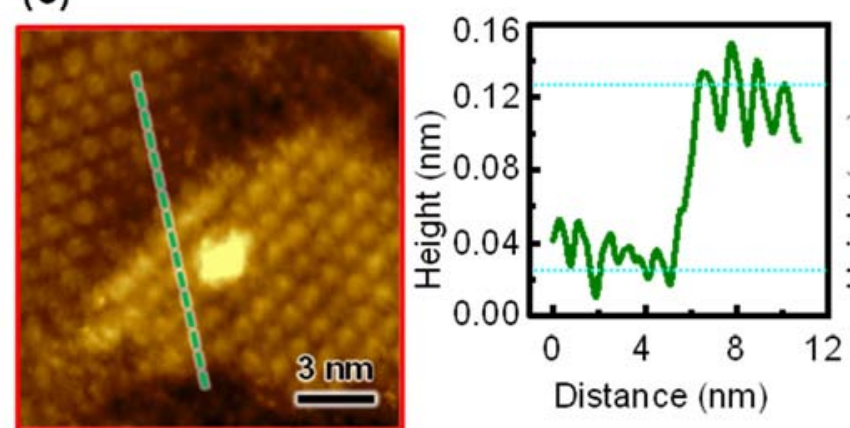

(b)
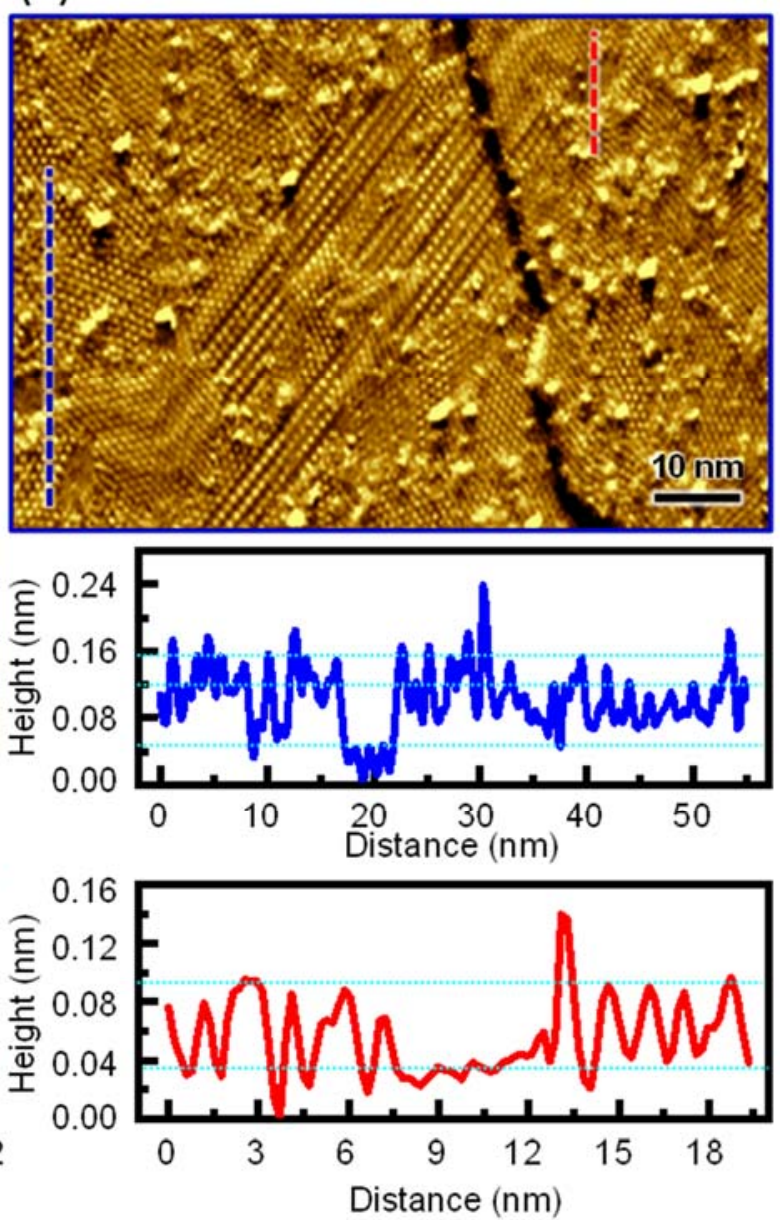

Figure S2. STM images of a $\mathrm{H}_{2} \mathrm{OEP}$ multilayer in (a) large-scale. Magnified images of (a) in blue (b) and red (c) color boxes $\left(\mathrm{V}_{\mathrm{s}}=-0.5 \mathrm{~V}, \mathrm{I}_{\mathrm{t}}=-200 \mathrm{pA}\right)$. 
(a)

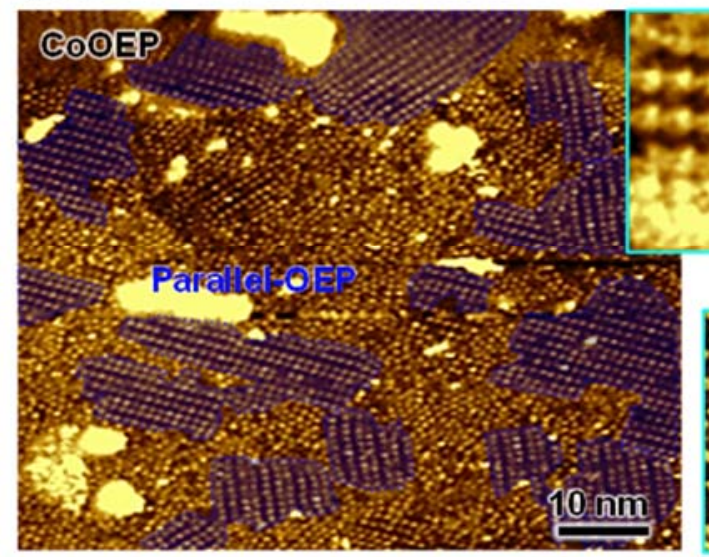

(b)

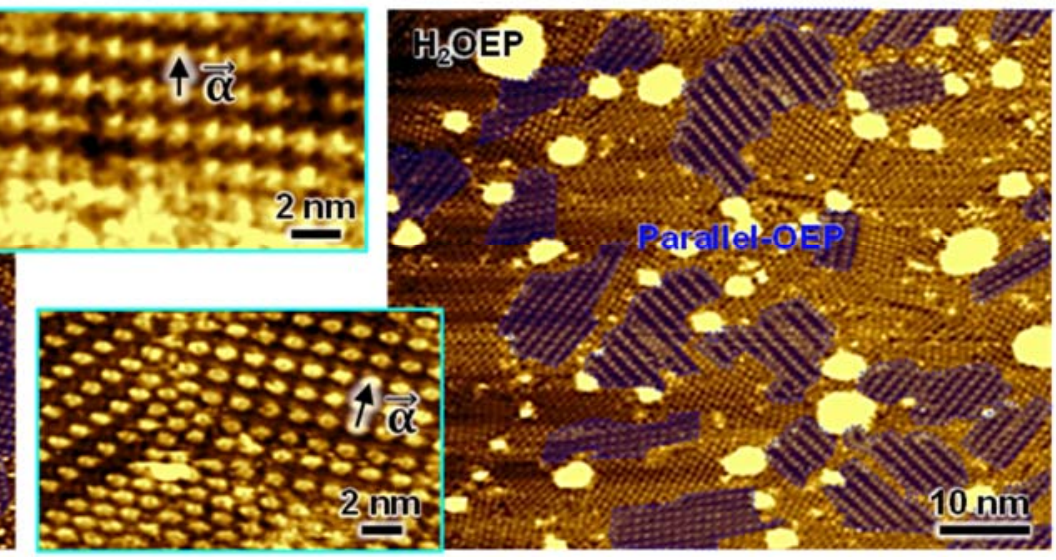

Figure S3. STM images of CoOEP and $\mathrm{H}_{2} \mathrm{OEP}$ self-assembled adlayer in octanoic acid in (a) $\left(\mathrm{V}_{\mathrm{s}}=-0.7 \mathrm{~V}, \mathrm{I}_{\mathrm{t}}=-300 \mathrm{pA}\right)$ and $(\mathrm{b})\left(\mathrm{V}_{\mathrm{s}}=-0.5 \mathrm{~V}, \mathrm{I}_{\mathrm{t}}=-350 \mathrm{pA}\right)$, respectively.

(a)
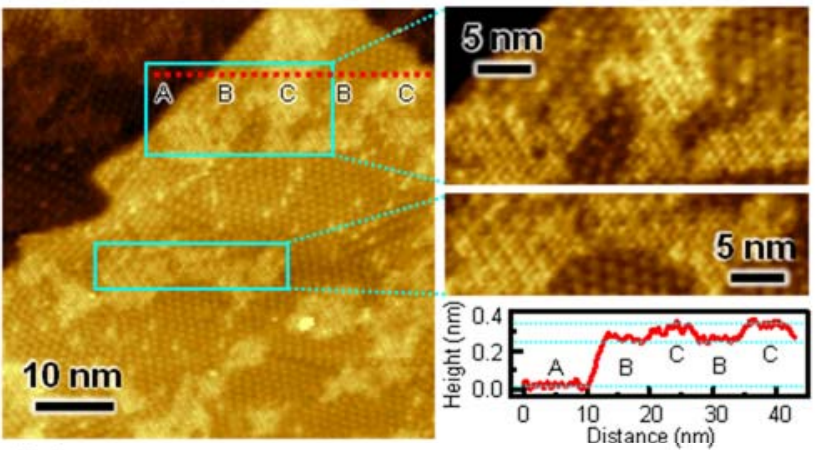

(b)

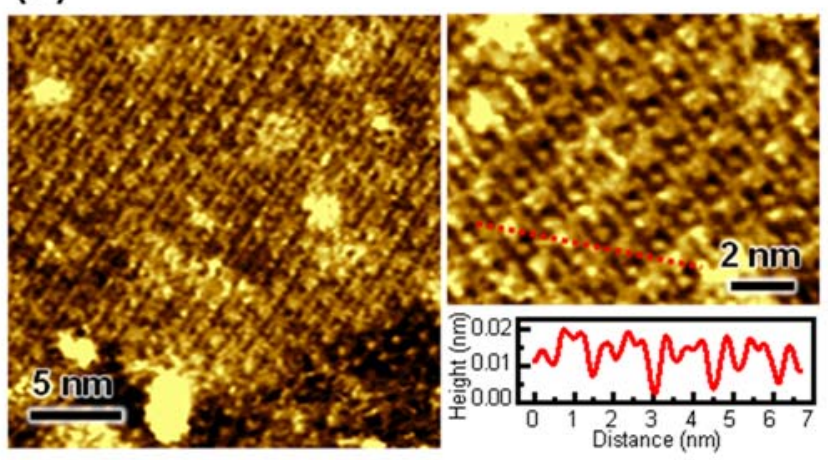

Figure S4. STM images of additional self-assembled adlayer on hexagonally assembled monolayer, which consists of added porphyrin and vertical co-adsorbed octanoic acid $\left(\mathrm{V}_{\mathrm{s}}=-0.7\right.$ $\left.\mathrm{V}, \mathrm{I}_{\mathrm{t}}=-300 \mathrm{pA}\right)$. 


\section{$\mathrm{H}_{2} / \mathrm{CO}$ OEP}
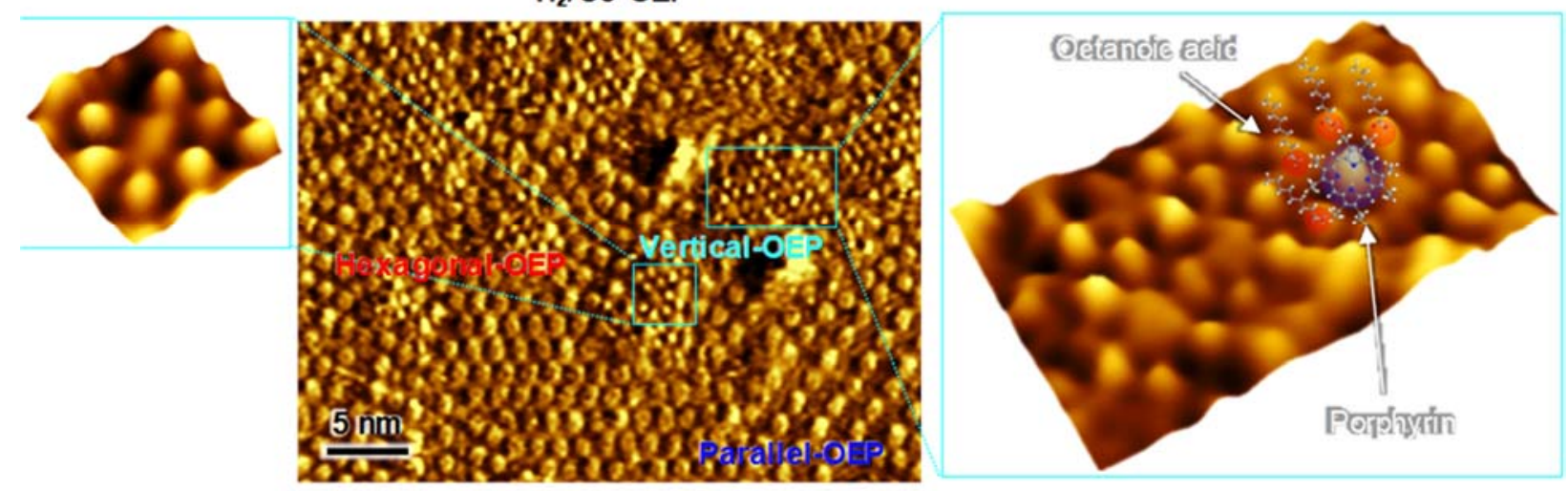

Figure S5. STM images acquired on $\mathrm{H}_{2} / \mathrm{Co}$ OEP surrounded by the vertically absorbed octanoic $\operatorname{acid}\left(\mathrm{V}_{\mathrm{s}}=-0.5 \mathrm{~V}, \mathrm{I}_{\mathrm{t}}=-300 \mathrm{pA}\right)$.
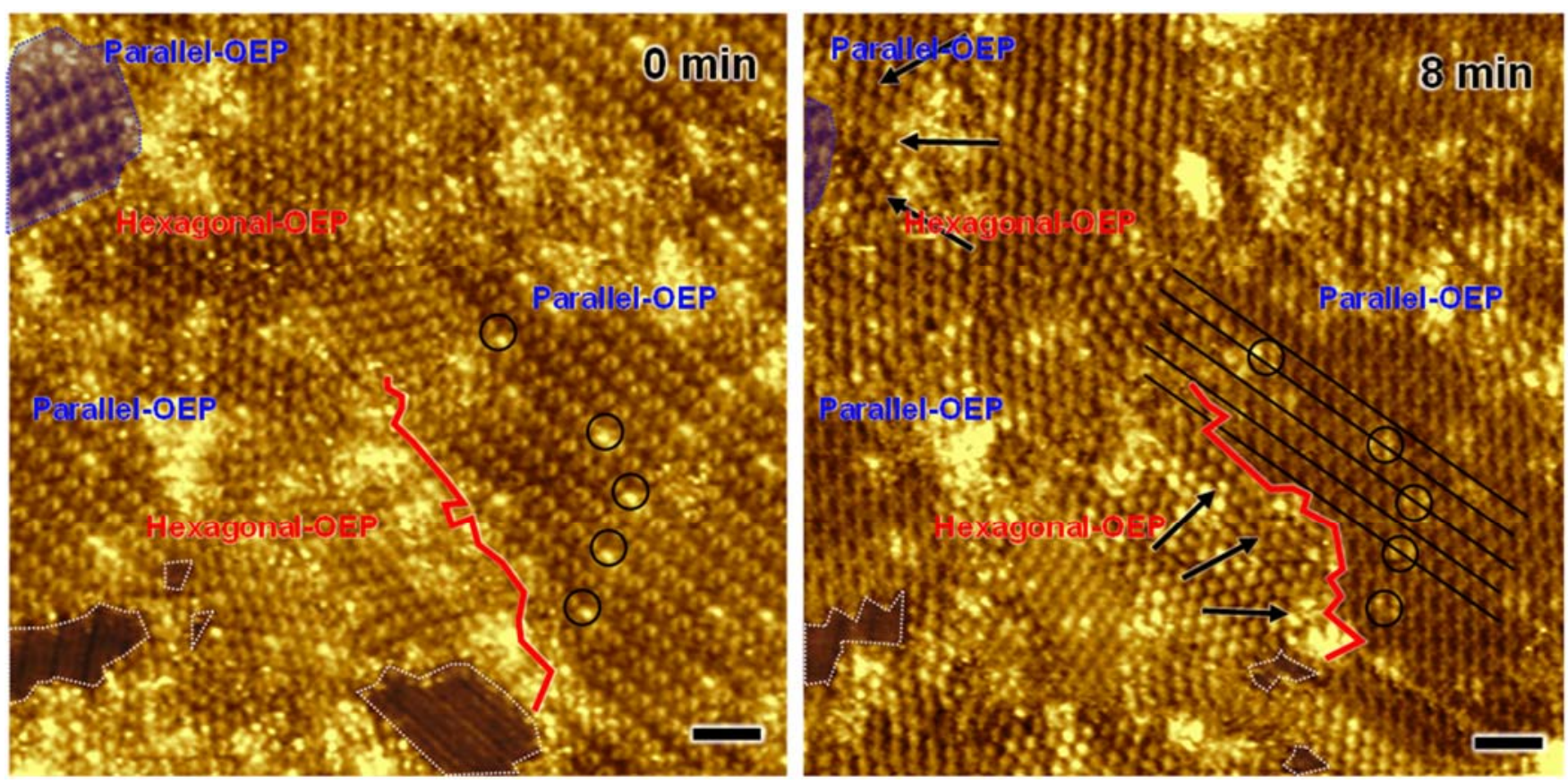

Figure S6. Sequential STM topographies of the transformation of surface structure at $\mathrm{H}_{2} / \mathrm{Co}$ $\mathrm{OEP}$ on $\mathrm{Au}(111)$. The black circles are specified reference points. The scale bar is $5 \mathrm{~nm}\left(\mathrm{~V}_{\mathrm{s}}=-\right.$ $\left.0.5 \mathrm{~V}, \mathrm{I}_{\mathrm{t}}=-350 \mathrm{pA}\right)$. 
(a)

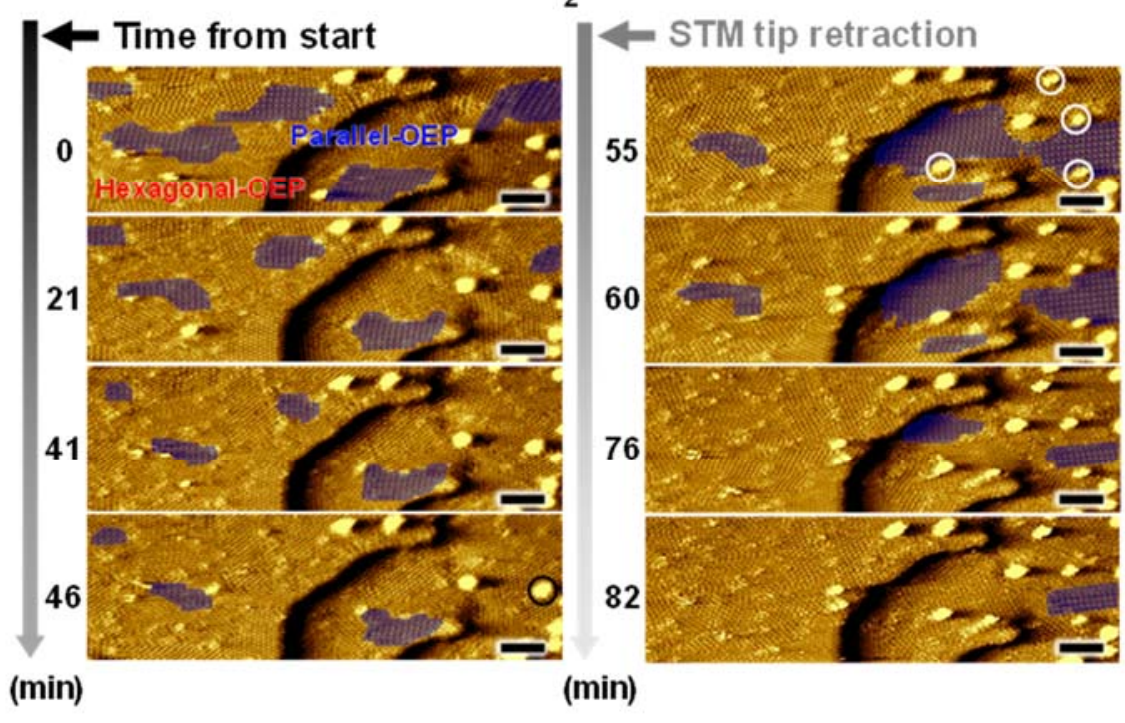

(b)

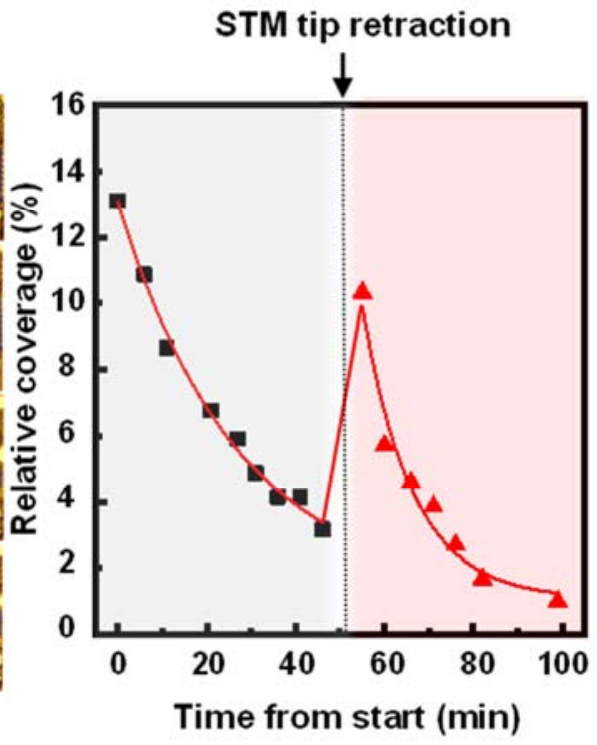

Figure S7. Series of sequential STM images of self-assembled $\mathrm{H}_{2} \mathrm{OEP}$ on $\mathrm{Au}(111) / \mathrm{mica}$ substrate as a function of time (minutes) in octanoic acid $\left(\mathrm{V}_{\mathrm{s}}=-0.7 \mathrm{~V}, \mathrm{I}_{\mathrm{t}}=-300 \mathrm{pA}\right)$ in (a). The islands marked with white lines and dark lines are newly emerged and disappeared islands, respectively. The scale bar is $10 \mathrm{~nm}$. (b) Relative coverage of Parallel-OEP as a function of time from the start of the STM measurement. The islands which are marked with white, and black circles are emerged and disappeared islands, respectively. We suppose that the islands are aggregates of the porphyrin molecules that are not participating the phase transition.

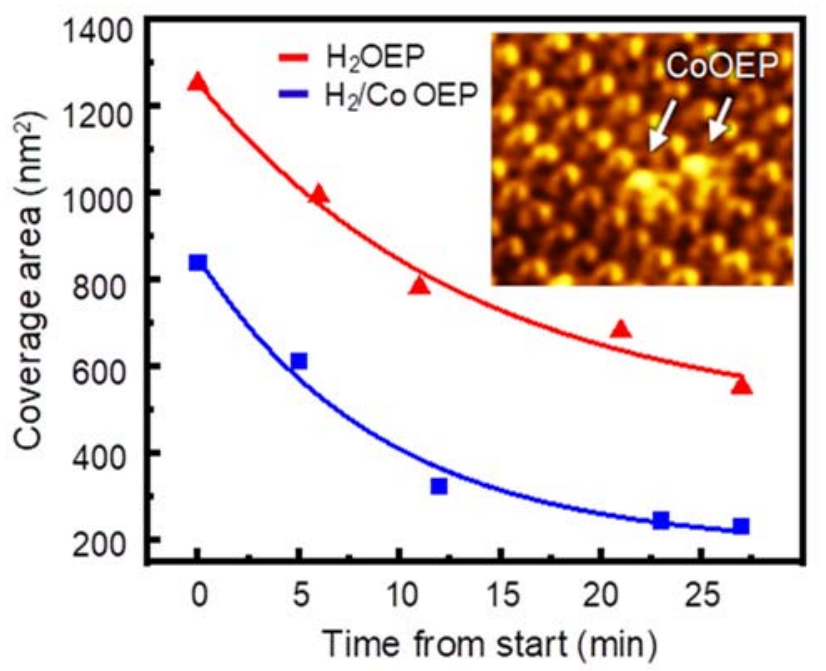

Figure S8. The change rate of coverage area from Parallel-OEP to Hexagonal-OEP as a function of time from the start of the STM measurement in $\mathrm{H}_{2} / \mathrm{Co}$ OEP (blue) and $\mathrm{H}_{2} \mathrm{OEP}$ (red). 

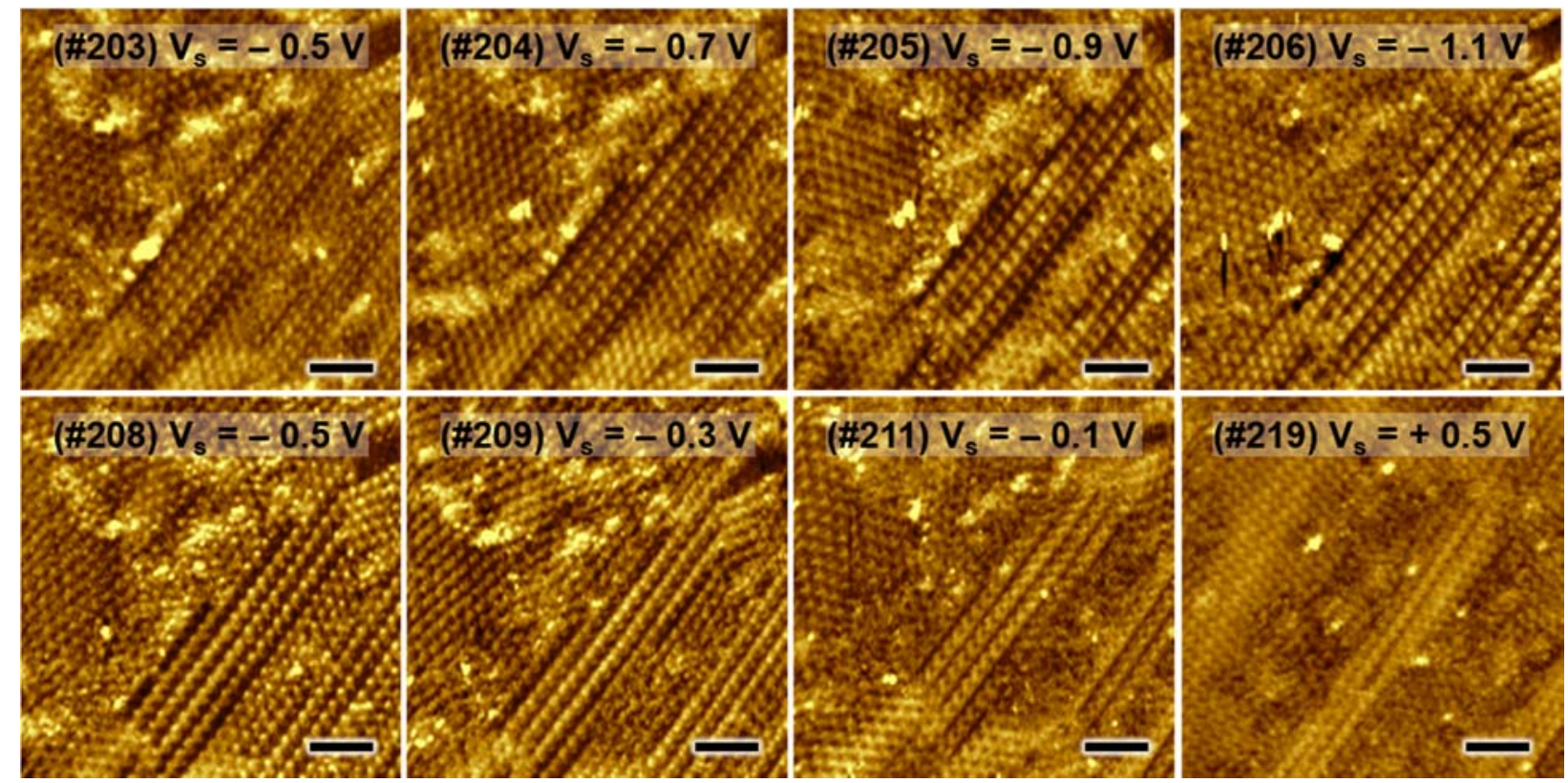

Figure S9. STM topography images under different tip bias. In each STM image, sample bias is indicated in a white box with the scan number. The scale bar is $5 \mathrm{~nm}$. 